\title{
The Importance of the Mesostructure in Toughening Cellulosic Short Fibre Composites
}

\author{
L. Savage ${ }^{1}$, K.E. Evans ${ }^{1}$ \\ ${ }^{1}$ College of Engineering, Physics and Mathematical Sciences, University of Exeter, \\ North Park Road, EX4 4QF, Exeter, UK
}

\begin{abstract}
In tonnage terms commercial production of engineering composites is dominated by glass reinforced systems, this is particularly the case in the automotive industry. Natural fibres have long been regarded as a viable lightweight replacement for glass, however the various shortcomings of natural/cellulosic fibres have so far, inhibited exploitation, where resistance to fast fracture during impact is a major failing.
\end{abstract}

Composite Mesostructure describe mid-scale structures in composites, such as fibre alignment patterns, bundling effects, and fibre end synchronisation. The Mesostructure can dramatically affect final properties in some random short fibre systems where flow is involved, such as sheet moulding compounds (SMC), and can be the determining factor in, e.g. the success of one fibre system over another. This study seeks to manipulate the fibre macrostructure in moulding compounds reinforced with cellulosederived fibres, where it is shown that by arranging mechanically inferior fibres in bundles, composite toughness can be drastically improved, and the reasons behind the toughening mechanism at work, is discussed. It is concluded that by controlling fibre morphology and mesostructure, some of the main barriers to wide exploration of natural fibres in engineering composites can be removed. 
Keywords: Mesostructure, Sheet Moulding Compounds, impact, toughness, Starch, filler, natural fibres, rayon, flax, particulate reinforcement, short-fibre composites, lightweighting.

\section{Introduction}

Glass fibres are the favoured reinforcement option on a cost/mechanical performance basis, and dominates worldwide engineering composite manufacture, where in tonnage terms, the GRP market is around 10 times the size of the nearest alternative [1]. The high density of glass has lead to considerable use of carbon fibre as a lightweight replacement, however at around 14 times the cost [2], cheaper alternatives such as natural fibres have long been considered as a potentially lightweight replacement fibre. The mechanical properties being reported for natural fibres indeed indicate a viable performance to match glass (e.g. tensile strength of flax 345-1035 MPa Young's Modulus 27.6 GPa Elongation to Break 2.7-3.2\% Density 1.5g/cm3) [3]. The problem is that natural fibres have a long list of well documented drawbacks, such as their inherent variability, crop-to-crop and type-specific differences, together with variability caused by individual processing/harvesting procedures. There are also supply chain issues and susceptibility to degradation of properties through moisture absorption, and poor adhesion between hydrophilic fibres and a hydrophobic matrix. The poor mechanical properties often reported for natural fibre composites are very often attributed to the shortcomings listed above [1]

It should also be pointed out that there are also, more fundamental drawbacks at work when one considers the structural arrangements of natural fibres, which are complex and hierarchical with degrees of order down to the nanoscale. Much of the past 
assessments of natural fibre engineering composites have employed the so-called "technical fibres" as the reinforcing phase. The technical fibre is simply a smaller part of a bast fibre bundle $[4,5]$ with dimensions of $50-100 u m$. The next level down is the "Elementary fibre" (sometimes referred to as ultimate or single fibre) which is one cell within the technical fibre. The technical fibre can be said to be a composite itself containing approximately 15-50 elementary fibres which are overlapped over a considerable length and glued together by the middle lamella, this consists mainly of pectin and hemicelluloses[5]. The arrangement between elemental and technical fibres is shown in figure 1.
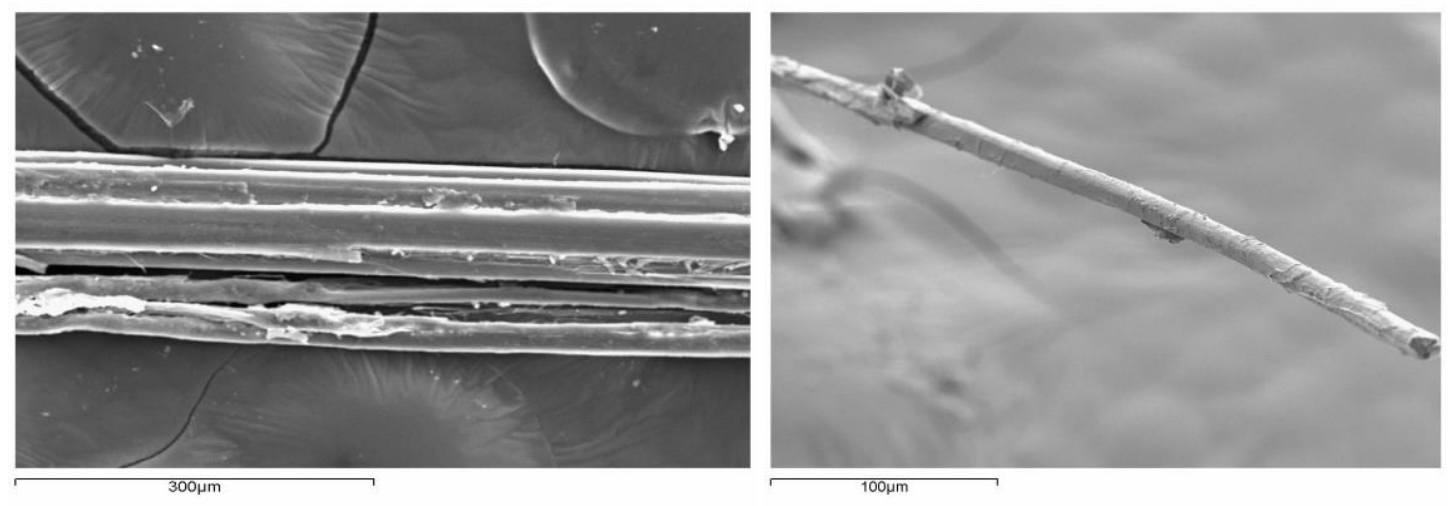

Figure1. Arrangement between the Technical fibres (left) and Elemental (right)

An elementary fibre has a diameter of approximately $20 \mu \mathrm{m}$ and a length up to $50 \mathrm{~mm}$. [5], and are therefore the same order of magnitude as single glass or carbon fibres. Elementary fibres are therefore routinely used as the test fibre in single fibre testing, where such tests give rise to the impressive mechanical properties often reported (see table 1).

The problem comes in realising these properties in composite structures. The reason for this is that the elementary fibres are locked within the hemicelluloses, lignin and pectin matrix, and are difficult to extract without damage to the fibres. As importantly, the 
elemental fibres themselves are not aligned to one another, and therefore the fibres cannot readily be cut to a set length, rendering any like-for-like comparisons with other synthetic fibre reinforcements misleading. The schematic in figure 2 illustrates the difficulties faced. Very many studies of NF as an alternative to glass in discontinuous fibre composites, have used technical fibres, which are then cut to some standard length and compared with glass of a similar length. Clearly, as seen in figure 2 , the cut lengths of the elementary natural fibres, would presumably follow a more Gaussian distribution of length sizes, and would also remain bound within a hemicelluose matrix. On this basis, the aspect ratio and hence reinforcing potential, of natural fibres would be substantially reduced. Even if the elemental fibres were freed from the hemicelluloses (e.g. by enzymic action or alkali treatment) the reinforcing properties of the fibres with a randomised length range, is hardly comparable to say, precisely cut glass. Evidently, little in the way of concrete conclusions about mechanical performance can be drawn from direct comparisons with industrial fibres, where it is not surprising that natural fibres fall short in terms of mechanical properties.

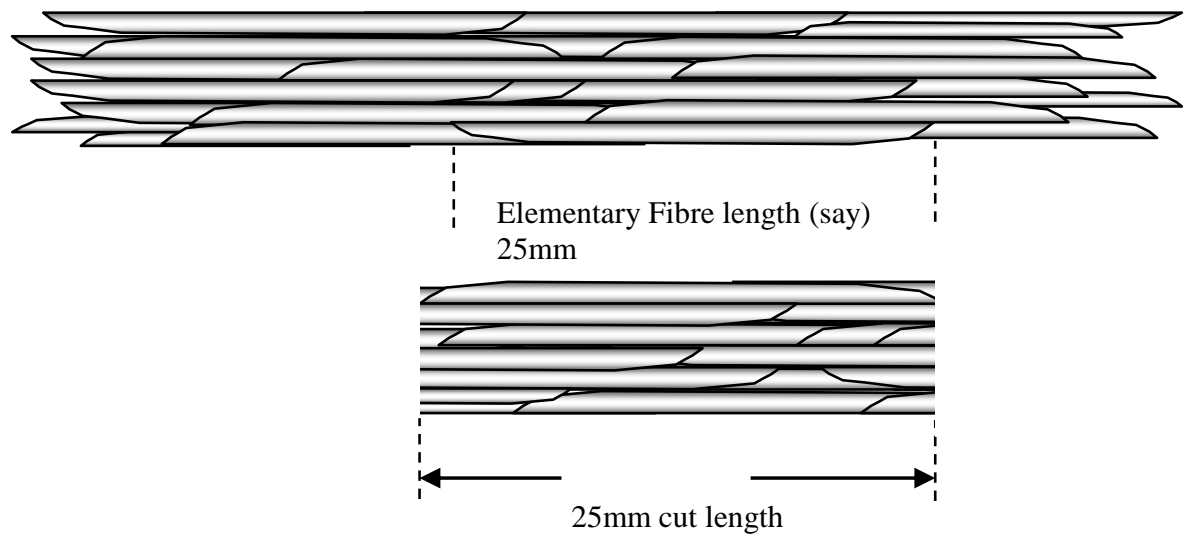

The main difficulty with working with natural fibres is not primarily as a result of their intrinsic properties or morphology of the elementary fibre, it is in controlling the 
reinforcement at the mesostructural level. This study seeks to avoid this problem by employing regenerated cellulose fibres as the reinforcement, and in this way gain some insight into the potentials offered by cellulosic fibres. The structure of regenerated cellulose (Cellulose II) has a semi-crystalline structure and, therefore, is composed of crystallites together with more disordered amorphous regions [6]. This arrangement differs substantially from the Cellulose I or native cellulose as found in natural fibres, It should be noted also, that the mechanical properties of regenerated Cellulose II (viscose or Rayon) are rather inferior to those reported for Cellulose I as found in common natural fibres. Table 1 details published property values derived from tests on elemental fibres, Table 2 presents our results from elemental fibre tensile tests on a representative group of both natural and synthetic fibres as used in this study. Both sets of results indicate that regenerated cellulose II is certainly less stiff than many natural fibres, and moderately strong in comparison with some types.

\section{Table 1}

Mechanical properties of natural fibres compared to glass and rayon (Except where shown, adapted from Bledzki \& Glassan1999 [7] \& Mohanty et al (2000) [8].)

\begin{tabular}{|c|c|c|c|c|}
\hline Fiber & Tensile strength (MPa) & Young's modulus (GPa) & Elongation at break (\%) & Density [g/cm3] \\
\hline Abaca & 400 & 12 & $3-10$ & 1.5 \\
\hline Bagasse & 290 & 17 & - & 1.25 \\
\hline Bamboo & $140-230$ & $11-17$ & - & $0.6-1.1$ \\
\hline Flax & $345-1035$ & 27.6 & $2.7-3.2$ & 1.5 \\
\hline Hemp & 690 & 70 & 1.6 & 1.48 \\
\hline Jute & $393-773$ & 26.5 & $1.5-1.8$ & 1.3 \\
\hline Kenaf & 930 & 53 & 1.6 & - \\
\hline Sisal & $511-635$ & $9.4-22$ & $2.0-2.5$ & 1.5 \\
\hline Ramie & 560 & 24.5 & 2.5 & 1.5 \\
\hline Oil palm & 248 & 3.2 & 25 & $0.7-1.55$ \\
\hline Pineapple & $400-627$ & 1.44 & 14.5 & $0.8-1.6$ \\
\hline Coir & 175 & $4-6$ & 30 & 1.2 \\
\hline Curaua & $500-1150$ & 11.8 & $3.7-4.3$ & 1.4 \\
\hline Viscose (cord) & 593 & 11 & 11.4 & 1.5 \\
\hline E-glass (Alumino-borosilicate) & $2000-5000$ & 70 & 2.5 & 2.5 \\
\hline
\end{tabular}

Table 2

Tensile results from single fibre tests on a range of elemental fibres. 


\begin{tabular}{ccc}
\hline Fibre & Tensile strength (MPa) & Young's modulus (GPa) \\
\hline Flax & 953 & 51.6 \\
Hemp & 690 & 49.7 \\
& & 4.24 \\
Rayon (Standard Viscose fibre) & 474 & 6.35 \\
High Tenacity Rayon Grade & 776 & 74 \\
SMC Grade E-glass & 2190 &
\end{tabular}

Regenerated cellulose or rayon fibres can be produced as a high tenacity technical fibre via a variation of the viscose process where the base feedstock material is wood pulp. Such yarns are essentially of higher strength and stiffness than conventional rayon fibre, and have been developed for use in engineering applications such as tyre reinforcement $[9,10]$.

Despite the lower stiffness and moderate strength, high tenacity rayon is useful, as an analogue for elementary natural fibres, where its use will allow manipulation of the mesostructure that manifests in the composite. Such fibres can be cut to length, bundled and coated, thus enabling direct comparison to glass fibre composites.

The most severe, and widely reported mechanical failing of natural fibre reinforcement when compared to glass, is low impact strength. The work of fracture demonstrated by NF composites are usually just a fraction of the value observed for corresponding glass reinforced composite (Newman [11]). Low impact properties of many natural fibre composites severely reduces their potential for substitution of non -sustainable materials such as glass [12]. The literature indicates that this situation is prevalent for very many natural fibre composite systems, both in thermoplastics and thermosets, irrespective of the matrix material used or the type of natural fibre studied. 
Natural fibre replacement of glass has been attempted many times in the past [13, $14,15,16,17,18,19,20,21]$. However, the most relevant and instructive studies have compared the NF composite mechanical properties directly with the properties of corresponding glass reinforced versions using the same manufacturing route. Sebe et al [22] examined RTM moulded Hemp/polyester composites, reported impact strengths of 7+ times lower than glass equivalents, while Rouison et al [23] also conducting hemp/polyester RTM, found a factor 12+ reduction in impact strength when comparing with like-for-like glass reinforced samples. Others have reported impact strength deficiencies of the same order [24, 25, and 26].

Sheet Moulding Compound (SMC) and Bulk Moulding Compound (BMC) is by far the largest type of thermoset used in the automotive industry today, where there is vast potential for a low cost, lightweight, and sustainable alternative to glass. Voorn et al [27] sought to develop flax fibre reinforced SMC, in order to produce lightweight versions that could match the performance of glass. Whilst stiffness and strength could be matched, impact strength was far lower, at 3-7 KJ/m2 compared to $40-70 \mathrm{KJ} / \mathrm{M} 2$ for glass in comparative tests. Huda et al [28] in a review of Natural fibre composites in the automotive sector, repeatedly details the shortcomings in impact performance demonstrated by natural fibre SMC composites, whereas in a study by Brouwer [29], a factor 5 decrease was observed in flax-reinforced SMC as compared to equivalent glass versions.

In summary, natural fibres in theory present viable alternative to E glass fibres, along with lightweight advantages. However, fundamental difficulties have so far hindered widespread application, the most serious of these, being a) the physical form taken by 
natural fibers which does not allow direct comparison with uniform length industrial fibres such as glass, and b) poor impact performance. This study seeks to obviate the problems associated with physical form, by using reconstituted cellulose fibre grades as an analogue for natural fibres. This will thereby allow direct comparison with E glass reinforced standard mouldings. Since rayon is a continuous fibre it can be cut to length, coated and bundled, just as E-glass is.

The ability to control the way in which fibres behave during moulding is believed to be critical. The vast majority of composite manufacturing processes involve some degree of flow, and in the case of SMC moulding compounds, flow is a critical part of the process where flow distances and can extend for a metre or more. The way in which fibres behave during flow, their degree of alignment with the flow pattern and direction, and the degree of local alignment in the composite, (or mesostructure) is thought to ultimately dictate the physical properties of the composite. Composite mesostructure describe mid-scale structures in composites, such as fibre alignment patterns, bundling effects, and fibre end synchronisation. The term is used by Piggott 1995 to describe mid-scale structures in composites in the size range $0.03-30 \mathrm{~mm}$ [30]. This study attempts to investigate the extent of this influence, determining how changes in mesostructure affect physical properties.

\section{Experimental details.}

Alterations in the composite mesostructure can be achieved by bundling fibres together, where several different coating types are investigated. Standard SMC and BMC composite production routes are used to produce a range of experimental versions, 
where four different types of natural fibres are examined, alongside several grades of reconstituted cellulose (or rayon) fibre, both in as received, and in bundled form. The resulting panels were then mechanically assessed and compared for their flexural properties and toughness, or dynamic (energy absorption) properties using the Charpy impact test. Such tests are standard mechanical evaluation techniques used in industry for SMC/BMC materials. Results were compared to equivalent glass-reinforced standard grade SMC/BMC. Samples of bundled rayon were then further assessed using micro-tensile tests in order to indicate the optimum bundle size required to maximize mechanical properties.

\subsection{Materials}

2.1.1 Fibres. The study examined the following four different natural fibre types: a) Long fibre flax in the form of hackled sliver (Albert Brille N.V. Belgium). This fibre was chosen because it offered the most refined and aligned form of the flax fibre. $b$ ) Aligned cut sisal (Ntiyiso Consulting, South Africa), c) Hemp aligned, low twist (Hemcore- now Hemp Technology Ltd, UK, d) Abaca or Manila hemp cordage (Local cordage suppliers). Two types of Rayon (viscose) fibre were also investigated: Standard viscose rayon regenerated cellulose fibre (Goonvean Fibres Ltd Devon UK), Cordenka 700 high tenacity rayon (Cordenka GmbH, Obernburg, Germany), - a regenerated cellulose in the form of cellulose II, produced through a variation of the standard viscose process. offering $10 \%$ higher strength compared to standard. The fibre is manufactured for use as reinforcement of high performance tyres. The benchmark standard glass reinforced SMC and BMC grades were produced using a standard SMC glass grade: MultiStar ${ }^{\mathrm{TM}} 254$ (John Manville) This is an assembled roving with silane based sizing formulated for use with unsaturated polyester resins. The elementary 
filament diameter was 15um (nominal). All Natural fibre and regenerated cellulose fibre samples were oven dried at $55^{\circ} \mathrm{C}$ for $48 \mathrm{hrs}+$ prior to specimen fabrication.

\subsubsection{Rayon fibre bundles:}

Samples of bundled rayon were supplied by Cordenka Cordenka GmbH, (Obernburg, Germany), The yarn used for samples was 250tex with an elementary fibre count of 1350, and zero twist. Bundling was achieved by the application of a sizing (or coating), to the cut yarns, where 2 coating types were examined:"S1" (PPL coating) and "S2" -a PVA coating (rhodopas ${ }^{\circledR}$ ). Both samples types were supplied in batches of $25 \mathrm{~mm}$ (see figure 3$)$ and also $6 \mathrm{~mm}$ lengths, to allow production of BMC (6mm) and SMC $(25 \mathrm{~mm})$.

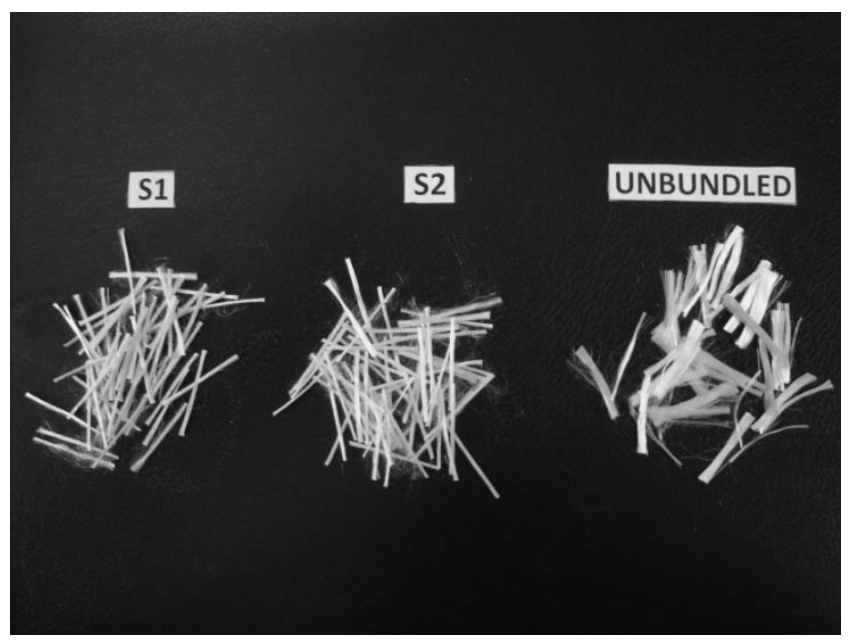

Figure 3 - Optical image of $25 \mathrm{~mm}$ bundled rayon samples

\subsubsection{SMC and BMC pastes}

SMC/BMC are composed of fibre-reinforced paste. The paste is itself, a formulation. Table 3 details types of raw materials that make up SMC/BMC paste formulations. All ingredients were provided by Menzolit UK and used as received, based on general purpose SMC/BMC formulations. The exact formulations used are the intellectual property of Menzolit UK and therefore it will not be discussed in detail, However, 
identical paste formulations was used throughout the study, where only the fibre reinforcement type were altered between batches.

\begin{tabular}{|c|c|c|}
\hline & SMC & $\mathrm{DMC}$ \\
\hline Polyester Resin & $\begin{array}{l}\text { 1) Derived from maleic acid and } \\
\text { standard glycols, dissolved in styrene 2) } \\
\text { A saturated polyester dissolved in } \\
\text { styrene. }\end{array}$ & $\begin{array}{l}\text { Derived from orthophthalic acid } \\
\text { and standard glycols, dissolved in } \\
\text { styrene }\end{array}$ \\
\hline Low-Profile Additive & $\begin{array}{l}\text { Liquid solution of polyvinyl acetate } \\
\text { (PVCa), dissolved in styrene }\end{array}$ & $\begin{array}{lll}\begin{array}{l}\text { Liquid } \\
\text { solution of polyvinyl }\end{array} & \text { of } \\
\text { acetate } & (\mathrm{PVCa}), & \text { dissolved in } \\
\text { styrene } & & \\
\end{array}$ \\
\hline Inhibitor & p-benzoquinone & p-benzoquinone \\
\hline Initiator & $\begin{array}{l}\text { t-BUTYL peroxyester type } \\
\text { organic peroxide }\end{array}$ & $\begin{array}{l}\text { t-BUTYL peroxyester type } \\
\text { organic peroxide }\end{array}$ \\
\hline Mould Release & Calcium stearate & Zinc stearate \\
\hline Filler & $\begin{array}{l}\text { Calcium carbonate, average } \\
\text { particle size of } \leq 5 \mu \mathrm{m}\end{array}$ & $\begin{array}{l}\text { Calcium carbonate, average } \\
\text { particle size of } \leq 5 \mu \mathrm{m}\end{array}$ \\
\hline Reinforcement & $\begin{array}{l}\text { Various (Benchmark standard: E-glass } \\
\text { fibre rovings cut to } 25 \mathrm{~mm} \text { lengths during } \\
\text { manufacture) }\end{array}$ & $\begin{array}{l}\text { Various (Benchmark standard: } \\
\text { Pre-chopped E-glass fibre rovings } \\
\text { of length } 6 \mathrm{~mm} \text { ) }\end{array}$ \\
\hline Thinkener & $\begin{array}{l}\text { Thickener Magnesium oxide, in liquid } \\
\text { form }\end{array}$ & No thickener required \\
\hline Wetting Agent & BYK® W-996 & Not required \\
\hline
\end{tabular}

Table 3 Types of raw materials used for SMC and DMC composite manufacture in this investigation

\subsection{Specimen manufacture}

All samples used the same BMC or SMC pastes (see above) where the various fibres examined were compounded at the same volume fraction as the standard glass

SMC/BMC used as the benchmark. (SMC $18.5 \%$ vol. fibre, BMC $12.3 \%$ vol.).

\subsubsection{Standard BMC compounding}

All BMC batches were mixed using a $1.5 \mathrm{~L}$ ' $\mathrm{Z}$ '-blade mixer. The control BMC batch was prepared using standard processing methods:

1) All the wet ingredients, (resins and catalyst etc), are mixed together for 5 minutes. 
2) Then all the remaining dry ingredients except the fibres are added and the paste is mixed for a further 20 minutes.

3) Finally the pre-chopped fibre samples (cut to $6 \mathrm{~mm}$ ) are added and the materials mixed for a final 3.5 minutes (unless otherwise stated).

After compounding the dough was discharged from the mixer and kept refrigerated in a sealed container for 24 hours before moulding.

\subsubsection{Standard SMC compounding}

Figure 4 shows the typical layout of an SMC production line, a well established production method for glass-reinforced thermoset composites. The pre-mixed paste containing all the resin and filler components is fed into the doctor boxes before the production run begins. A constant layer of the paste then covers the carrier films as they are drawn through the doctor box system, and a layer of the particular fibres under test, is then sprinkled randomly onto the bottom carrier film, before it and the top pastecovered carrier film are sandwiched together to form the final SMC mouldable sheets. The sheets are then stored at $35^{\circ} \mathrm{C}$ for $48 \mathrm{hrs}$ to allow the thickening process to proceed. SMC sheets, and also BMC dough mixes, are then compression moulded.

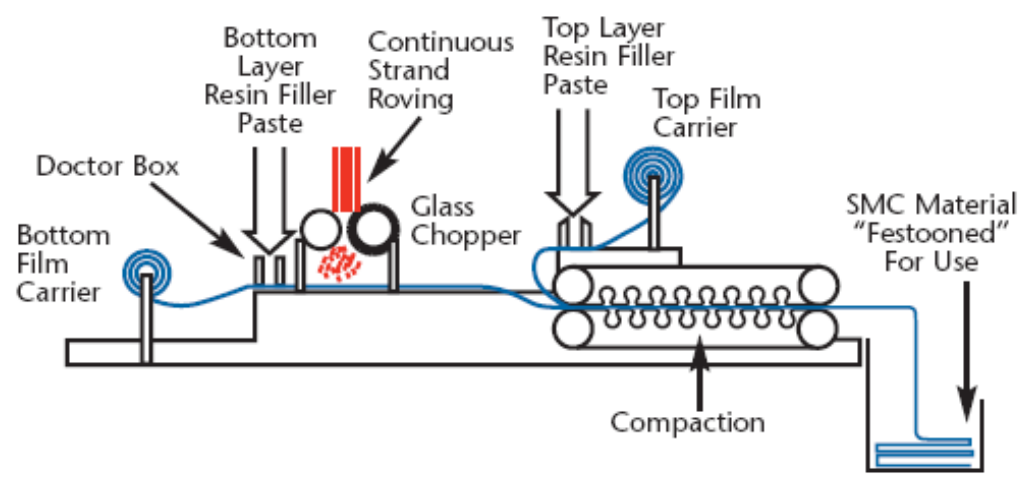

Figure 4. Schematic diagram of an SMC manufacturing line. 


\subsubsection{Moulding}

For each SMC and BMC formulation three flat panels of dimensions $25 \times 25 \times 4 \mathrm{~cm}$ were moulded, for each of the different formulations, two batches were manufactured separately, to minimise the effect of batch to batch variations. Compression moulding was performed with a hot press, where all formulations were cured at $145{ }^{\circ} \mathrm{C}$ and a pressure of $4.1 \mathrm{MPa}$ for 3 minutes, replicating the curing conditions of the standard SMC/BMC composite.

\subsubsection{Fibre bundle tensile samples - manufacture}

Fibre tensile experiments were conducted using glass, rayon and flax fibre bundles. The matrix used was a typical BMC/SMC paste (see table 3). Sample fibre bundles were constituted where the number of elementary fibres per bundle was varied from 1-70+ fibres. Each bundle sample was prepared by aligning the requisite number of individual elementary fibres in a jig. Uncured paste was then applied to the upper and lower surfaces of the bundle. Samples were then pressed and cured at $145^{\circ} \mathrm{C}$ as per usual SMC/BMC manufacturing procedure.

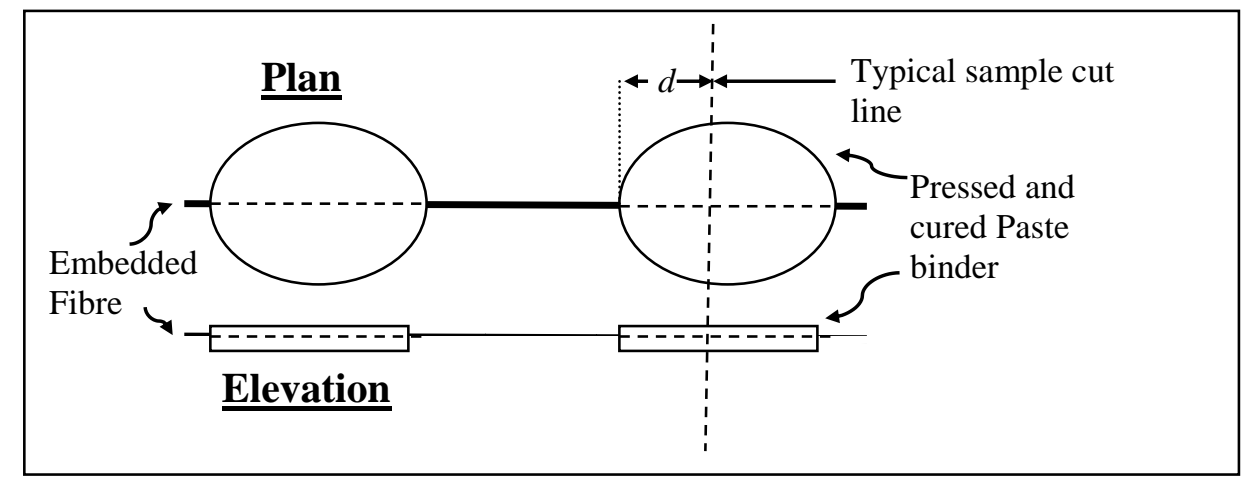

Figure 5. Schematic diagram of micro-tensile test specimen arrangement. 
This sample preparation procedure allowed the testing of the fibre matrix bond as found in typical BMC/SMC composites, and assured excellent wetout of the fibre, giving an optimised fibre/matrix bond. The cured paste formed a hard, well-compacted pellet around the fibre bundle, and could be used as the end tabs for clamping in the microtensile machine. Figure 5 shows a representation of the pressed sample. One end (the test end) of each sample was then cut using a diamond saw to give a prescribed embedded length $(0.5-3 \mathrm{~mm})$. The study allowed the effect of bundle size on mechanical behaviour to be assessed. Bundle size was plotted against work of fracture for each sample calculated from area under the load-displacement curve [31].

\section{Testing}

\subsection{Flexural testing}

Three-point flexural testing was conducted in accordance with ISO178 using a Lloyd Instrument EZ20 and a $500 \mathrm{~N}$ load cell, with test performed at an extension rate of 1.9 $\mathrm{mm} / \mathrm{sec}$. A total of 16 samples were tested for each reformulation, with eight samples cut from two of the four cured panels. The sample size used was 80x10x4 mm.

\subsection{Impact testing}

Charpy impact tests were carried out using a Ceast Resil Impactor Junior with a noninstrumented $4 \mathrm{~J}$ impact head. Samples were prepared and tested in accordance with ISO179-1 standard. a total of 20+ samples per batch were tested, where samples were taken from several test panels. The sample size used was 80x10x4 mm. 


\subsection{Fibre bundle micro-tensile Tests}

Fibre micro-tensile tests are routinely conducted in order to assess the interfacial bond strength between fibre and matrix. This study had an additional objective - to ascertain the optimum (or minimum) bundle size required to induce matrix failure in cured samples of SMC/BMC paste, where only this aspect of the study will be reported here. The micro-tensile testing machine used was a Biax-200 Micromaterials ultra low load tensile test machine. The load during tests was recorded by a $10 \mathrm{~N}$ load cell (Transducer World) and the displacement of the sample recorded by a linear variable displacement transducer (LDVT), both of which were interfaced with a computer so that the results were recorded and could be analysed further. A microscope was positioned directly above the test grips and connected to digital video camera, the real-time image of the test setup from the camera was output on a PC monitor. This image allowed accurate mounting of every individual test specimen and live monitoring of the test's progress.

\section{Analysis}

Optical microscopy Optical microscopy was used to examine impact fracture surfaces, and observe fibre bundles.

Scanning electron microscopy (SEM). The SEM examinations of the fractured samples were performed using a Hitachi S-3200 N scanning electron microscope. All samples were given a $4 \mathrm{~nm}$ gold coating to reduce surface charging.

\section{Results and discussion}

Figures $6 \& 7$ plots the flexural modulus and strength data for each of the BMC test panels. The results are compared to standard glass BMC. These are typically of low 
fibre volume fractions in the range of $12.5 \%$. This means that specimen modulus would be predominantly a matrix property. This is borne out in the results where changing the fibre reinforcement does not dramatically affect stiffness. In contract, it is expected that the flexural strength performance should be directly related to fibre strength. This relationship is clear in the flexural strength results e.g. unreinforced BMC (matrix only) is a fifth of reinforced grades and glass fibres with over double the intrinsic strength; demonstrating a corresponding doubling in flexural strength compared to cellulosic fibres. Figure 8 presents associated Charpy impact data for each sample where the weakness in impact of natural fibres is clear; the best NF samples absorb a fraction of the energy absorbed by the glass standard grades. The magnitude of the disparity points to a fundamental difference in failure mechanism between glass and NF reinforced samples. SEM and optical examination were used to compare fracture surfaces (see figures $9 \& 10)$. In all glass samples, protruding fibres at the fracture surfaces were evident, indicating reduced fibre breakage where crack propagation took place predominantly within the matrix region. NF fracture surfaces appeared cleanly cleaved, indicating fibre breakage. Clearly stronger fibres such as glass are able to constrain crack propagation to the matrix, where the deflected cracks must then follow a more tortuous and energetically costly path around strong fibres. It follows that one method of toughening NF or cellulosic composites would be to increase the strength of fibres. A simple way to do this is to increase the diameter of individual elementary fibres or by bundling fibres together. The Cordenka Rayon samples are high strength grades where improved impact resistance is evident in the results. A further more substantial improvement is demonstrated by Bundling. The $\mathrm{S} 1$ and $\mathrm{S} 2$ bundled samples show twice the impact resistance of corresponding randomly distributed rayon fibre samples. 
Comparing fracture surfaces from bundled and un-bundled rayon samples (Figure 10), it is evident that the stronger bundles have deflected cracks in a similar fashion to glass. It should also be noted however, that the BMC process involves high shear mixing, where this action is known to cause the bundled fibres to break up and disperse somewhat. In Figure 11 the effect of this is plainly demonstrated, where bundled samples were subjected to progressive increasing mixing times. Increased shear through mixing leads to bundle break up and a corresponding drop in impact resistance. Mei and Piggott [30] reported a similar effect when studying SMC material exposed to different degrees of flow (during the moulding process). It was observed that as the degree of flow during moulding increased, so the toughness was reduced. It was suggested that this was due to the breakdown of fibre bundles. In contract to the BMC process, the sheet moulding compound (SMC) process involves no mixing stage where bundled fibres remain largely intact during manufacture. Consequently, improvements in impact energy absorption are more pronounced, where fibre bundling leads to a factor of 5 improvement over non-bundled (or dispersed) versions. (see Figure 12). A similar toughening effect has been reported by several researchers in the past [32 33 34]. In addition, glass composite manufacturers select surface coatings (sizes) for glass rovings that control the degree of fibre dispersion. It is reported that the use of sizings that are insoluble in the matrix, result in tighter bundles that produce tougher composites.[35, 36]. Fibre bundling seems to be a highly interesting method for toughening composites made from mechanically inferior natural/cellulosic fibres, however no work in the area has been reported until now. In a review of fibre bundling in short fibre composites by Mulligan in 2003 [37], it is evident that almost all of the past work focused on glass reinforced composites. The review concludes that although fibre bundling effects are 
known, the relationship between the degree of bundling and mechanical properties, was at that time, not well understood or investigated. The review goes on to present a method of making samples with a closely defined bundle architecture in order to study these effects, however work in the area has since largely ceased.

In this particular study the authors had no control over the bundling procedure, and the number of fibres per bundle (or bundle dimension). This is thought to be an important factor; Figure 15 compares the dimensions of rayon bundles as used in this study with standard glass roving using in SMC. Clearly the rayon bundles are far larger, where each bundle is made up of 500+ hundred of elemental fibres. The situation causes inhomogeneity in the resulting composite and correspondingly, more variation in properties, this is characterised by the large error bars in the results presented in Figure 12. Similar effects have been reported by other researchers [37] where increase in inhomogeneity of composite material due to bundling leads to large variations in local volume fraction. It follows that composite properties could further improved by a more homogeneous structure, where fibre bundle size is optimised to be as small as possible whist still demonstrating sufficient strength to resist fracture and confine crack propagation to the matrix. Micro-tensile tests on bundled fibres, can provide additional information on the optimised bundle size for each fibre type. Figure 16 plots the variation in work of fracture with number of fibres in the bundle for glass. When the fibre bundles are larger than 10-12 fibres, behaviour changes; fibre fracture tends to cease and is replaced by fracture within the matrix.

Figures 17 and 18 show similar plots for Flax and Rayon, where the number of fibres required to deflect cracks is higher. Fibre failure ceases at around 20-30 fibres in flax 
and 40+ fibres in Rayon - reflecting the intrinsically low strength of these fibres compared to glass. (see single fibre tensile results indicating that rayon is a quarter to a fifth of the strength of E glass).

\section{Conclusions}

BMC and SMC composites are characteristically low fibre volume fraction materials widely used in the automobile industry, for appliances, in construction, furniture and electrical/electronic components. Impact strength or toughness, in these materials is a critical property, where failure is predominantly within the matrix, and matrix properties are the dominating factor. However, the composite mesostructure does play a part, where features such as fibre bundling affects the way cracks propagate. Because cracks cannot pass through bundles, as they would individual fibres, but must divert around such obstacles, the crack path length is increased, resulting in heightened energy absorption. Fibre bundling offers a potential toughening technique that can be applied to mechanically inferior reinforcements such as natural fibres, where many past studies have shown toughness is a major drawback in considering such fibres as a replacement for glass. This study has demonstrated the toughening effect in BMC and SMC, and provided information on the likely optimum bundle size required for cellulosic fibres to be used in such systems.

\section{Acknowledgements}

The Authors would like to thank the following organisations for providing materials to the study: Samuel N Mokoena Enterprise Development Ntiyiso Consulting (South 
Africa), Goonvean Fibres Ltd (Devon UK), Albert Brille NV, Westward Rope \& Wire Service Devon UK, Hemp Technology Limited (Norwich UK), Cordenka GmbH (Obernburg Germany), \& Menzolit Ltd UK Burnley UK. Also the UK Technology Strategy Board TP Number AB 121A.

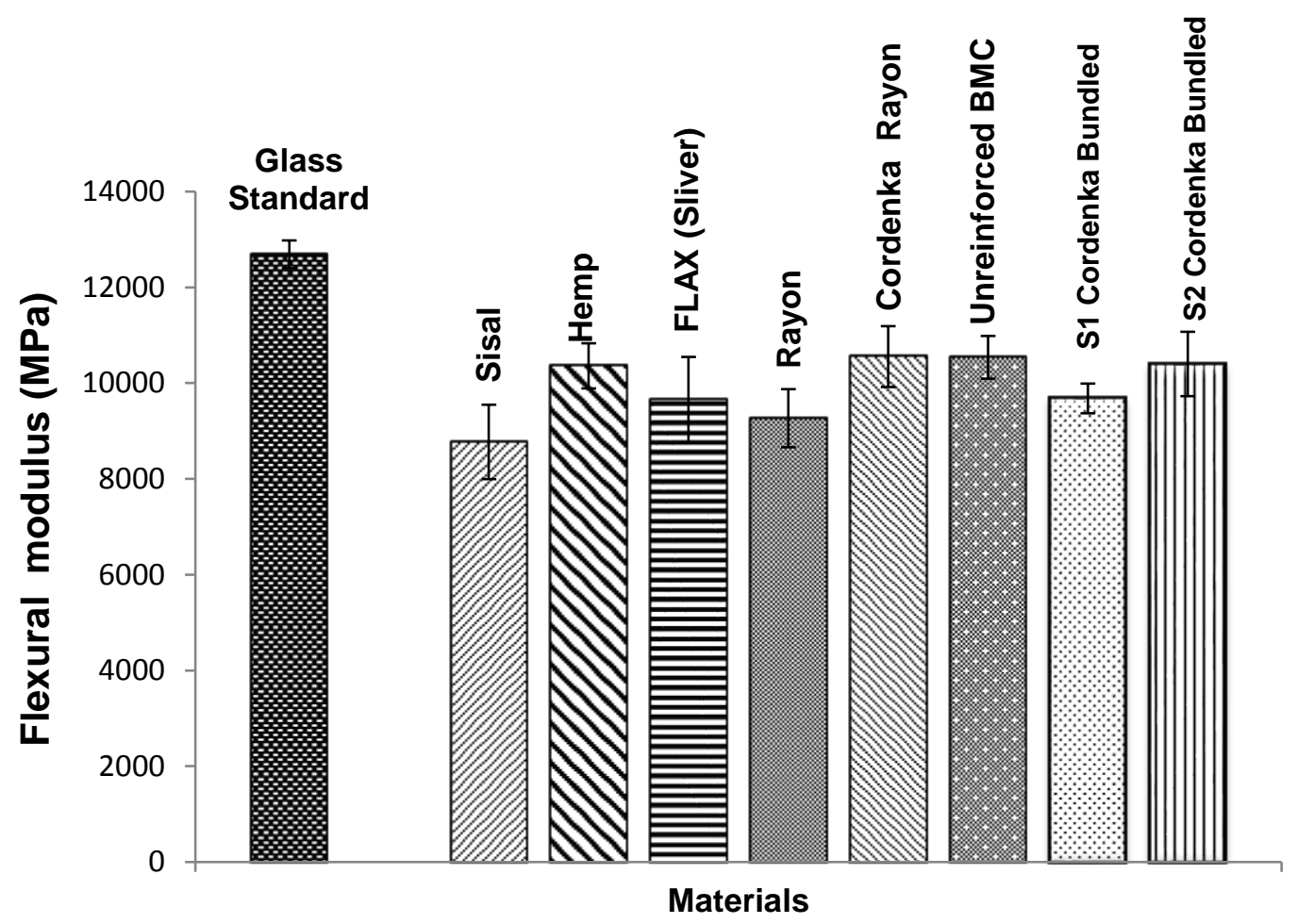

Figure 6. Flexural modulus results for a range of fibre reinforced BMC composites. (Error bars signify 1 standard deviation) 


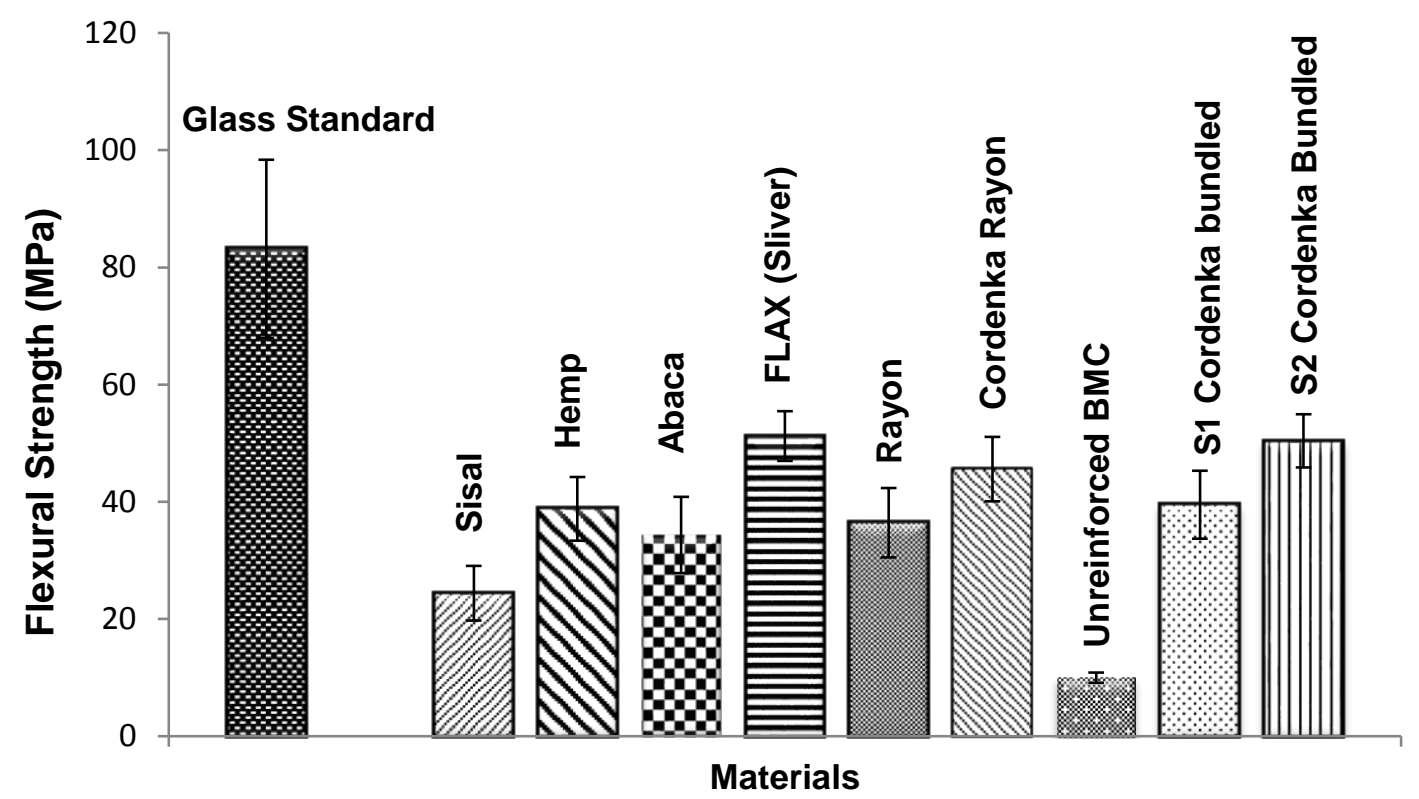

Figure 7. Flexural strength results for a range of fibre-reinforced BMC composites. (batch Error bars signify 1 standard deviation) 


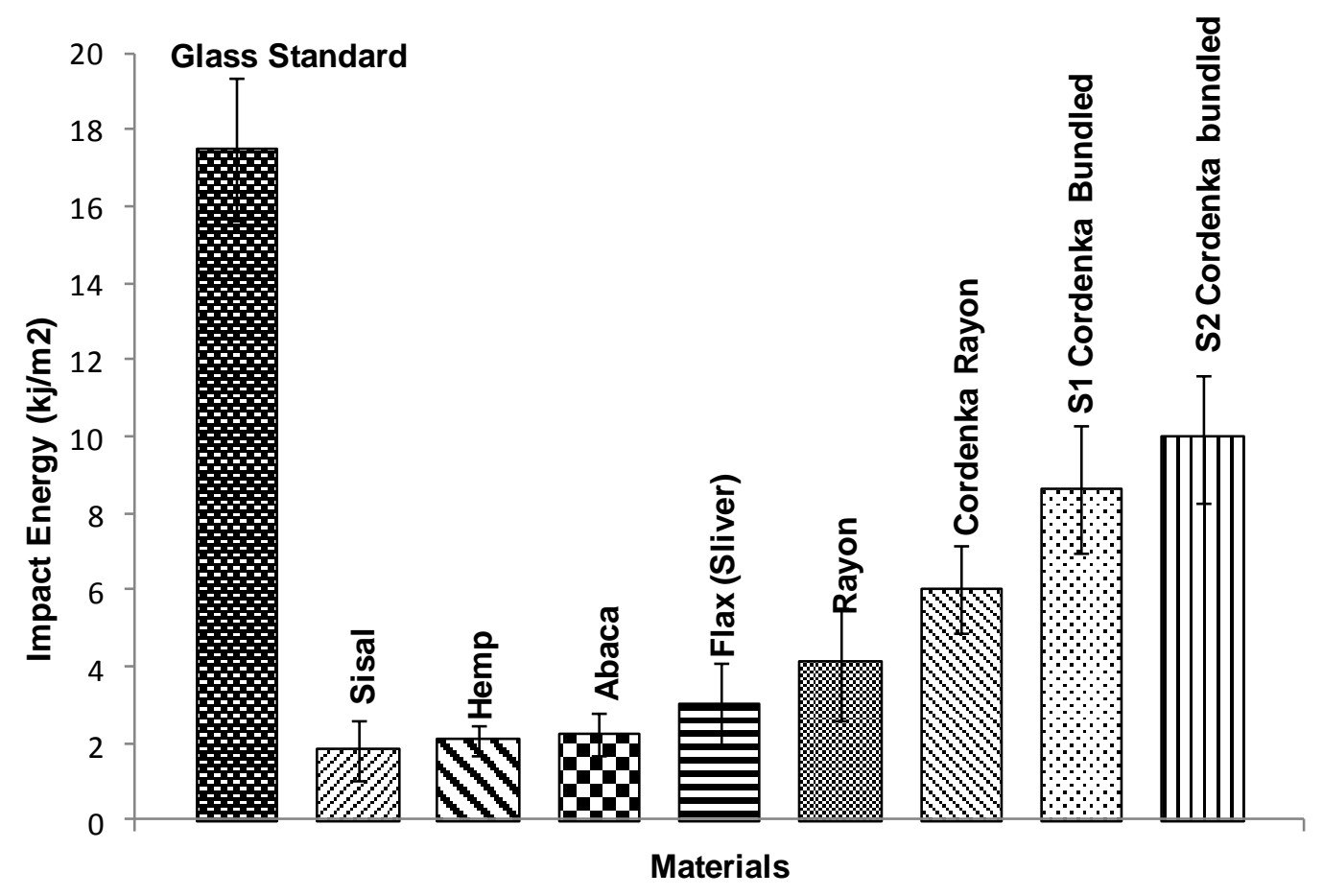

Figure 8. Charpy impact results for a range of fibre-reinforced BMC composites. (Error bars signify 1 standard deviation)
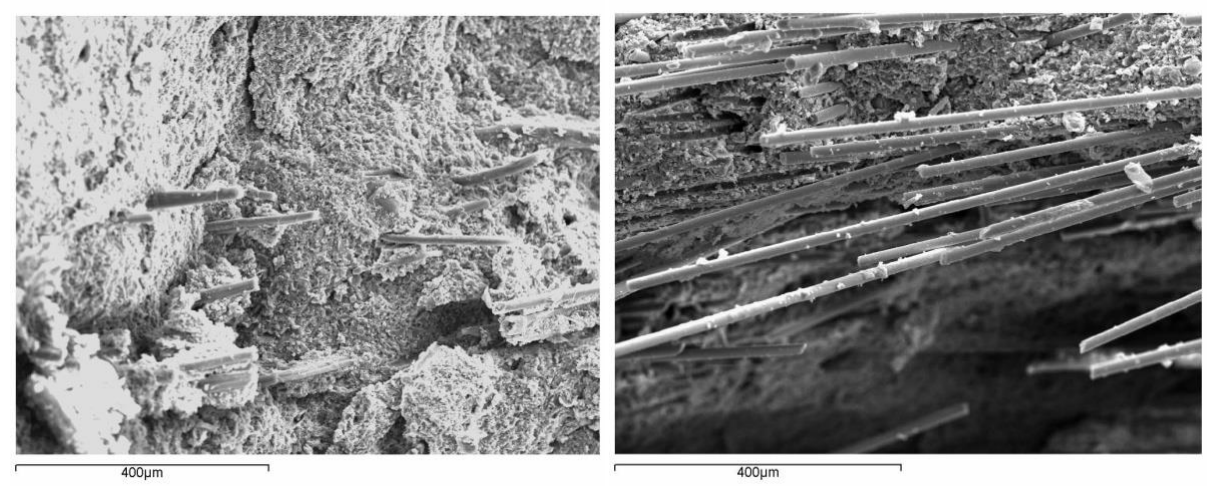

Figure 9.SEM of impact fracture surfaces for Flax (left) \& Glass (right).
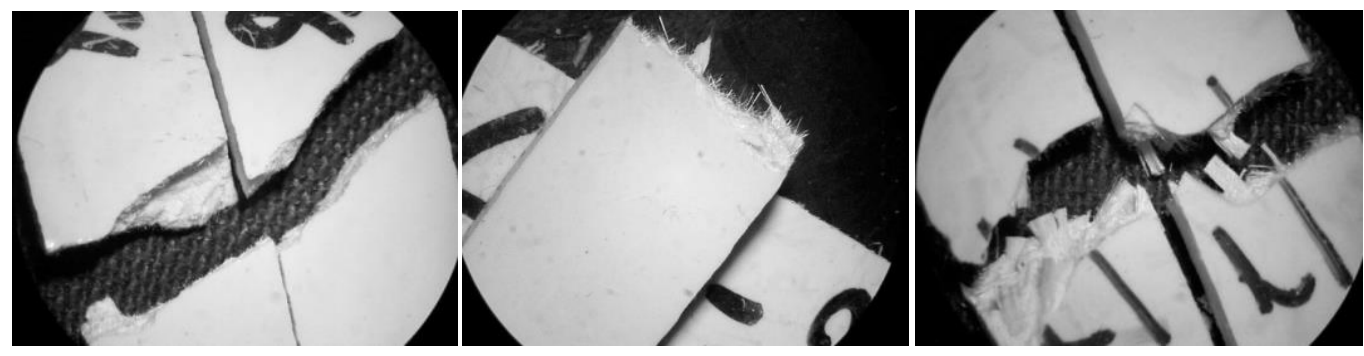

Figure 10 Optical Images of Impact Fracture surfaces. (Right: Cordenka rayon nonbundled, Middle: Cordenka Rayon Bundled, Left: Glass Standard showing protruding fibres. 


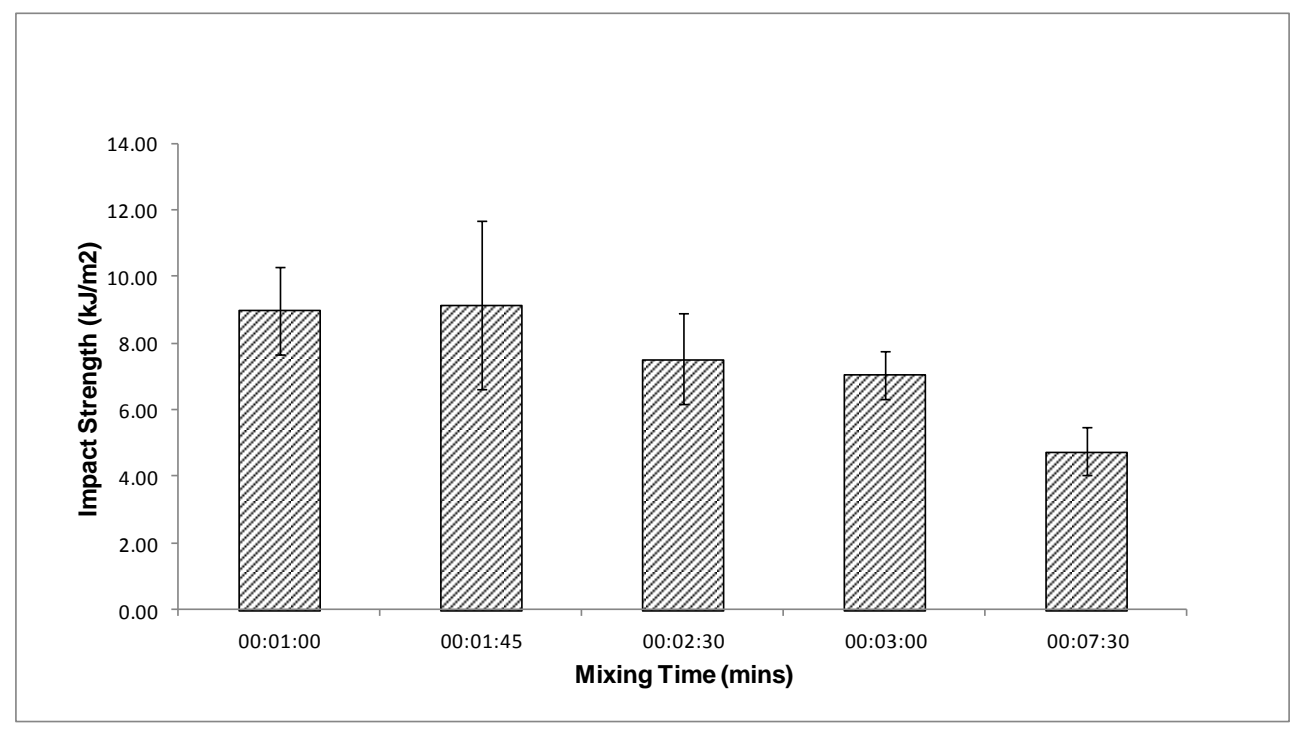

Figure 11. Charpy impact results for bundled rayon samples showing the effect of mixing times in BMC composites.(Error bars signify 1 standard deviation)

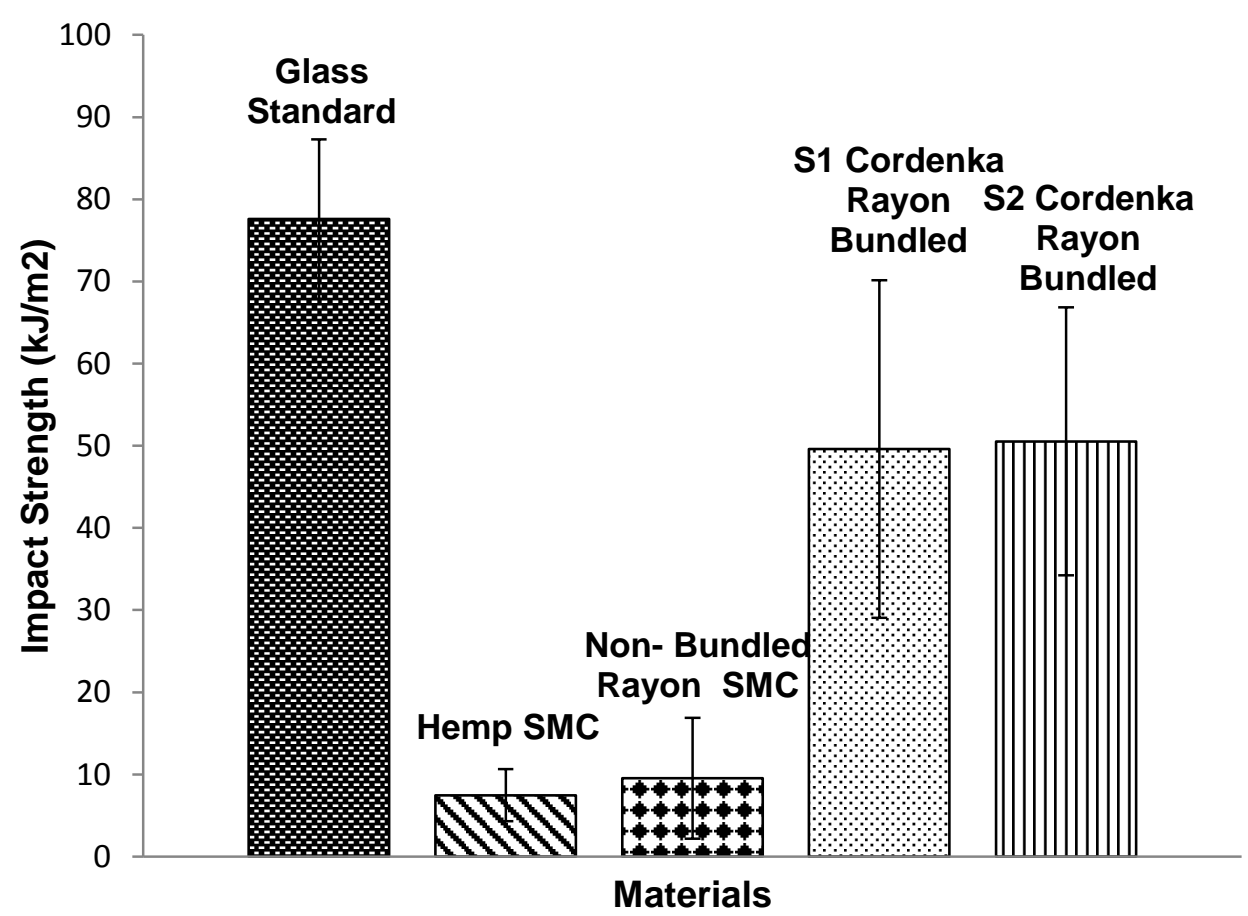

Figure 12. Charpy impact results comparing several bundled and non- bundled SMC composites. (Error bars signify 1 standard deviation) 


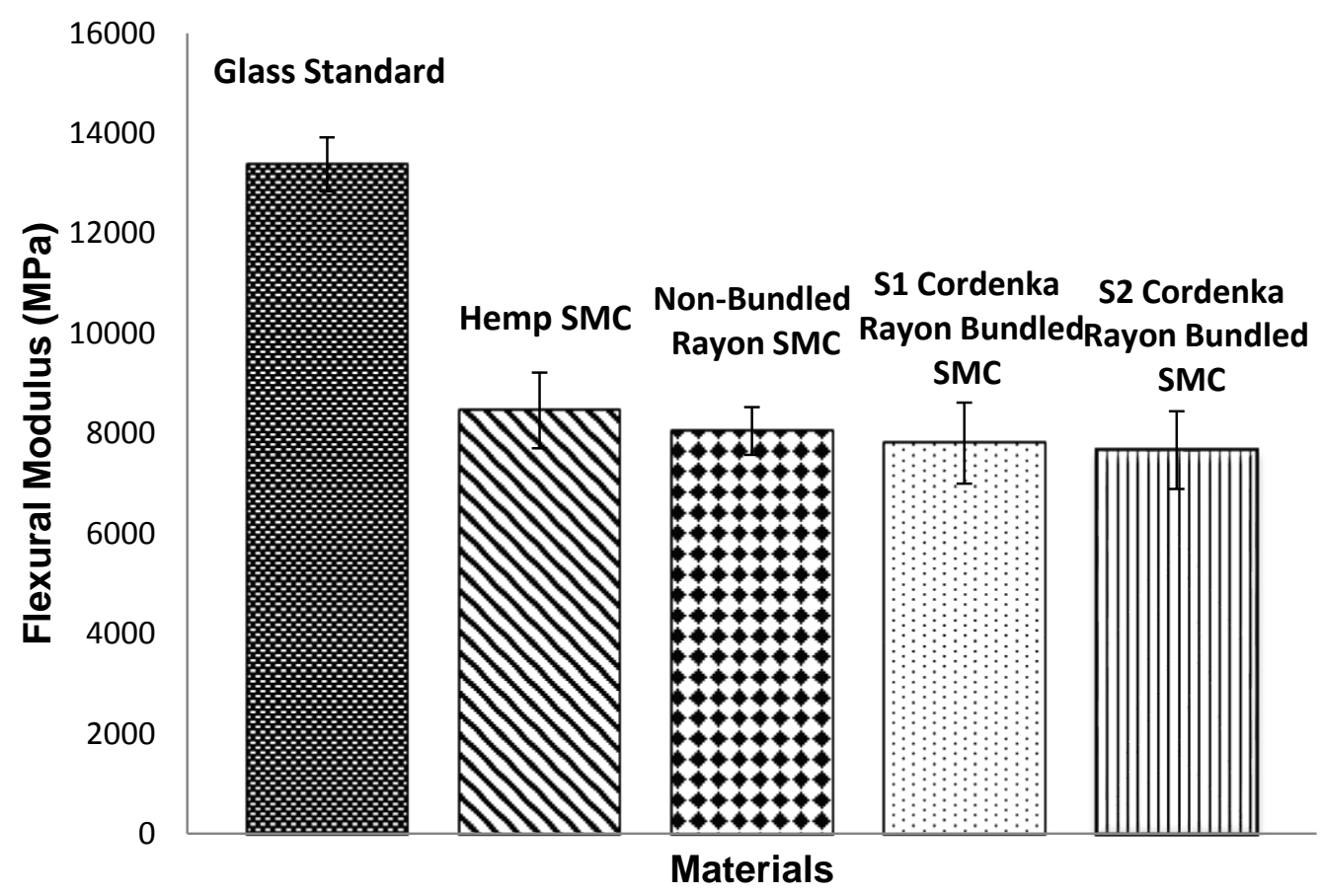

Figure 13. Flexural modulus results comparing several bundled and non- bundled SMC composites. (Error bars signify 1 standard deviation).

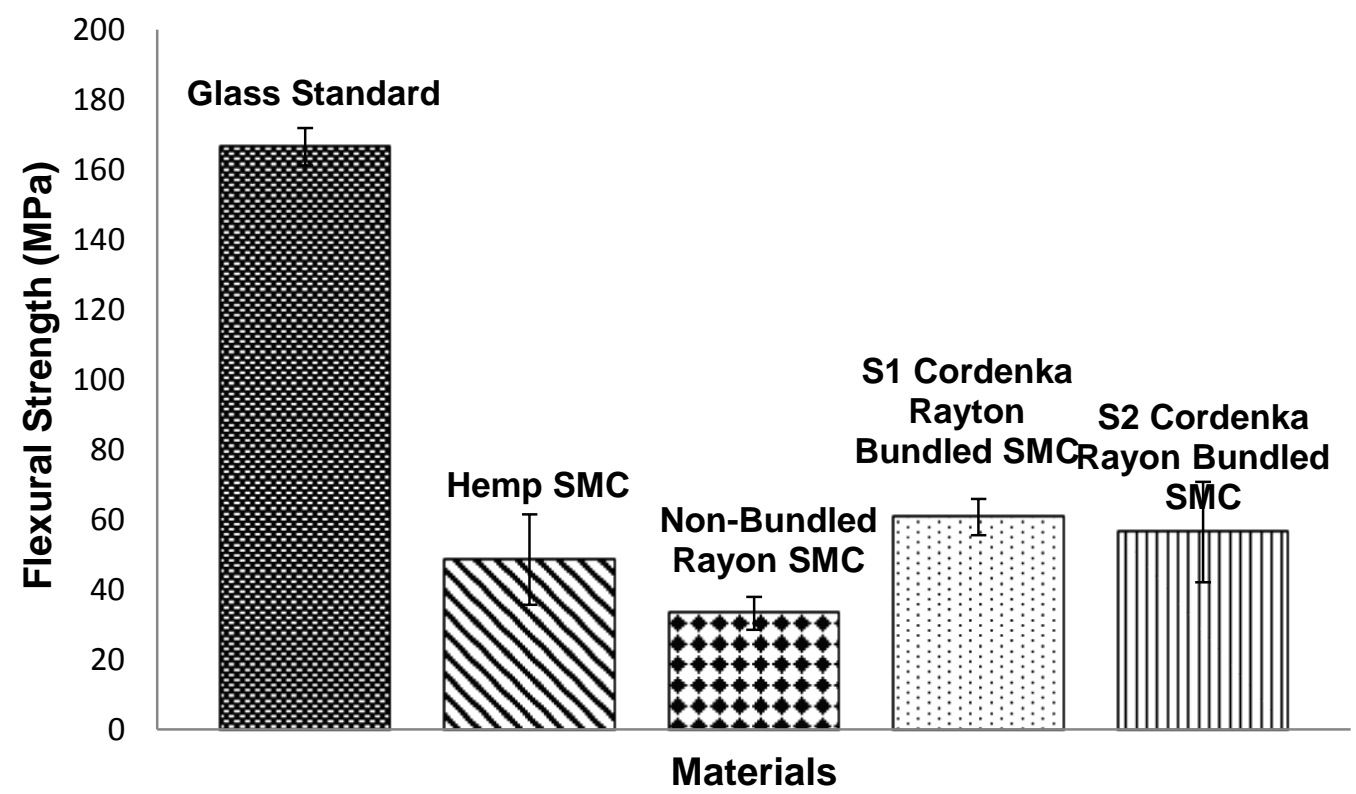

Figure 14. Flexural strength results comparing several bundled and non- bundled SMC composites. (Error bars signify 1 standard deviation) 

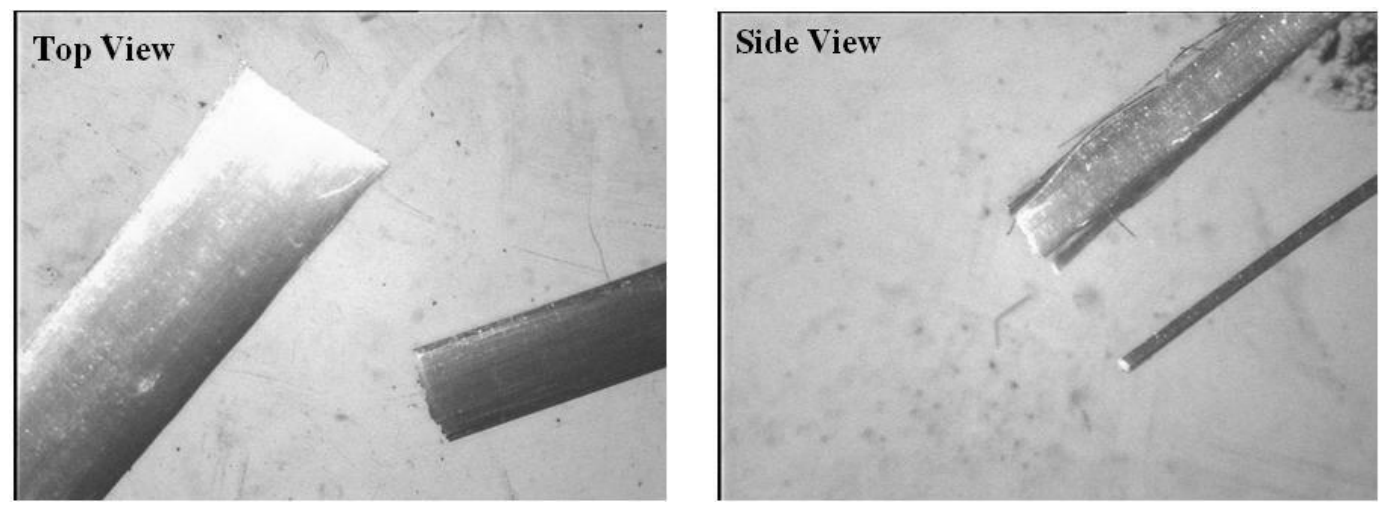

Figure 15. Optical images comparing rayon fibre bundles (left) with standard glass roving (right) showing the dimensional disparity.

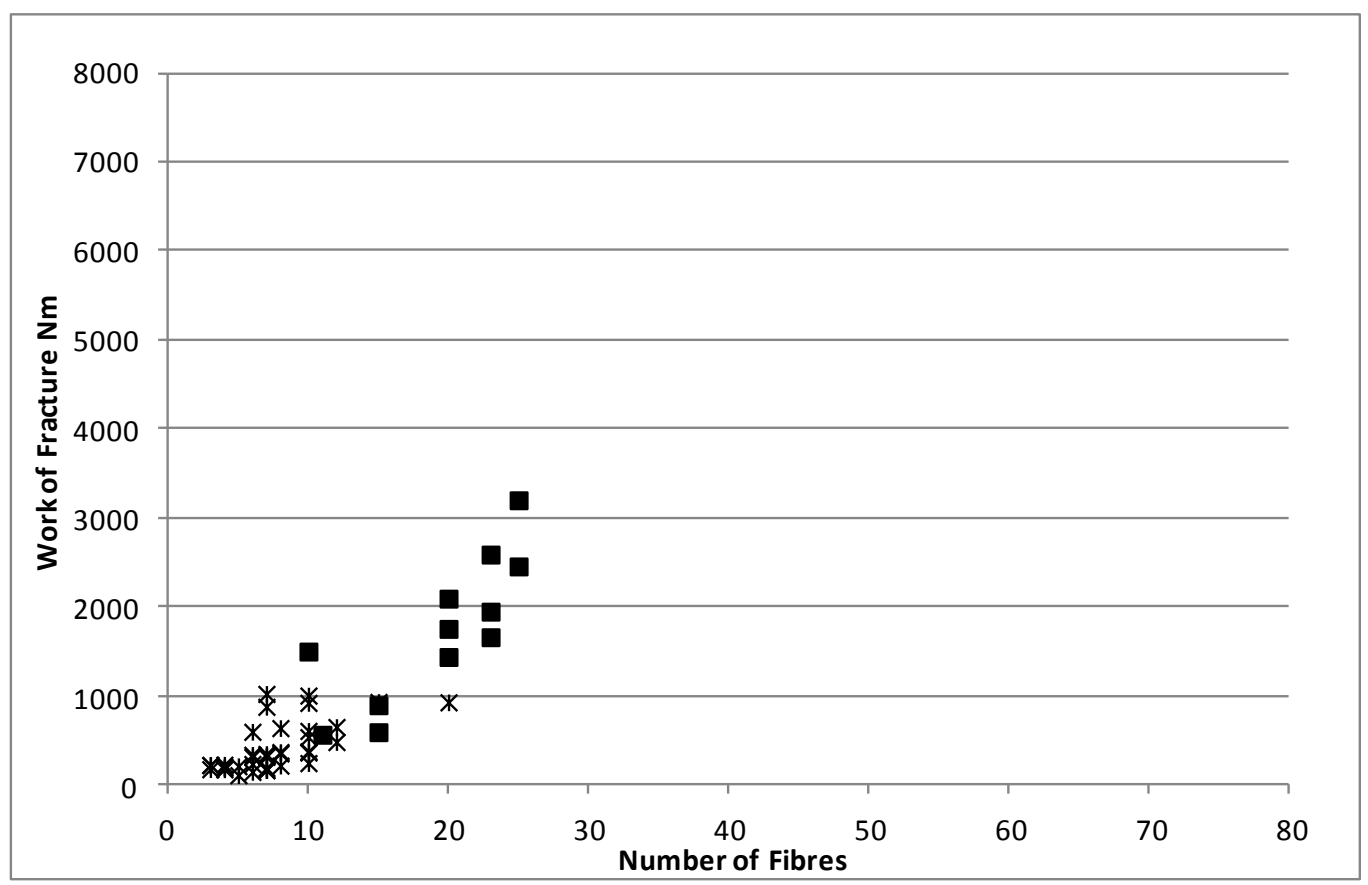

Figure 16. Micro tensile tests on Glass Fibre bundles- Work of Fracture vs Number of fibres/bundle. ( $*=$ Fractured fibre samples, $\mathbf{\square}=$ Matrix Failure Samples). 


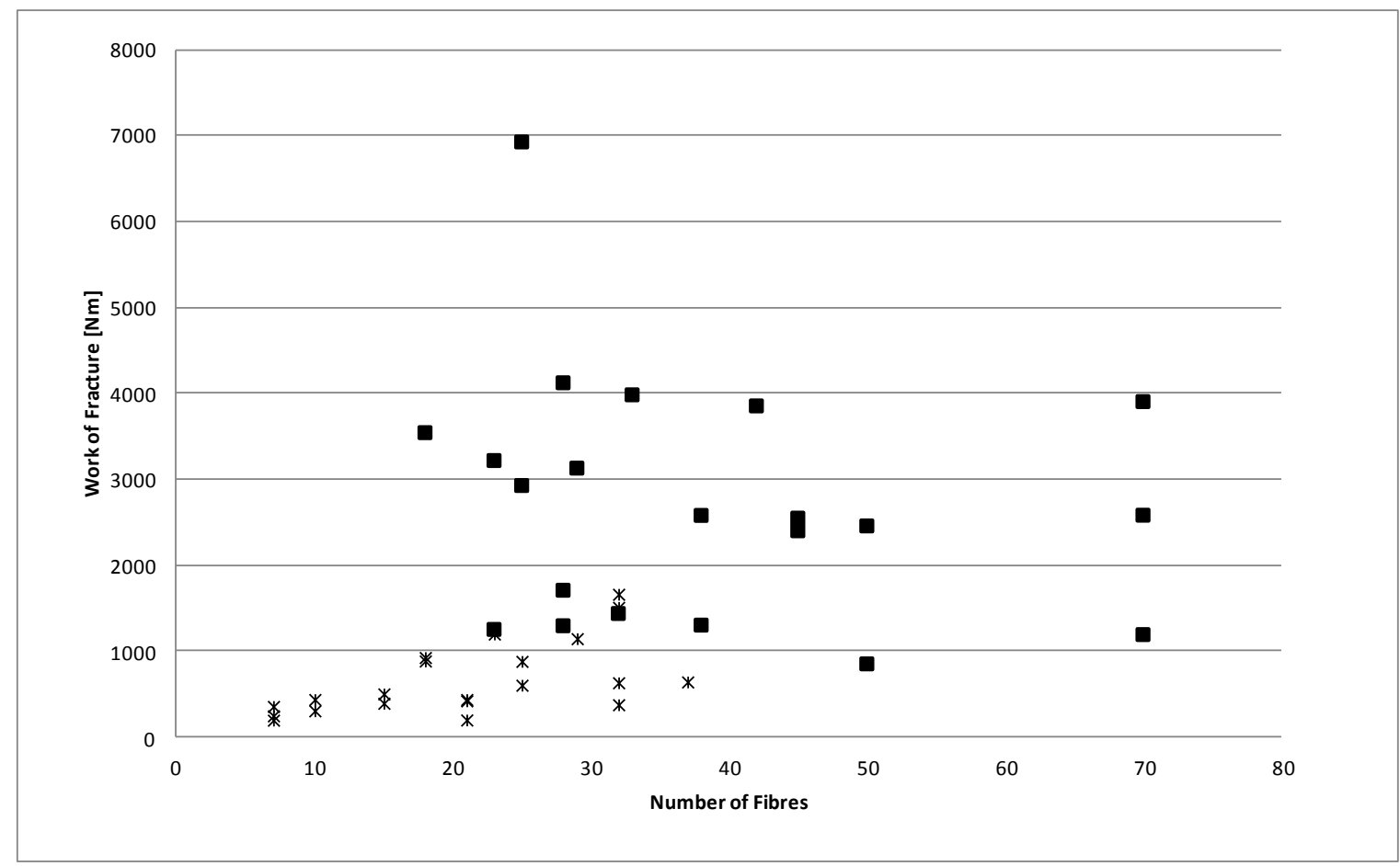

Figure 17. Micro tensile tests on Flax Fibre bundles- Work of Fracture vs Number of fibres/bundle. ( $*=$ Fractured fibre samples, $\mathbf{\square}=$ Matrix Failure Samples).

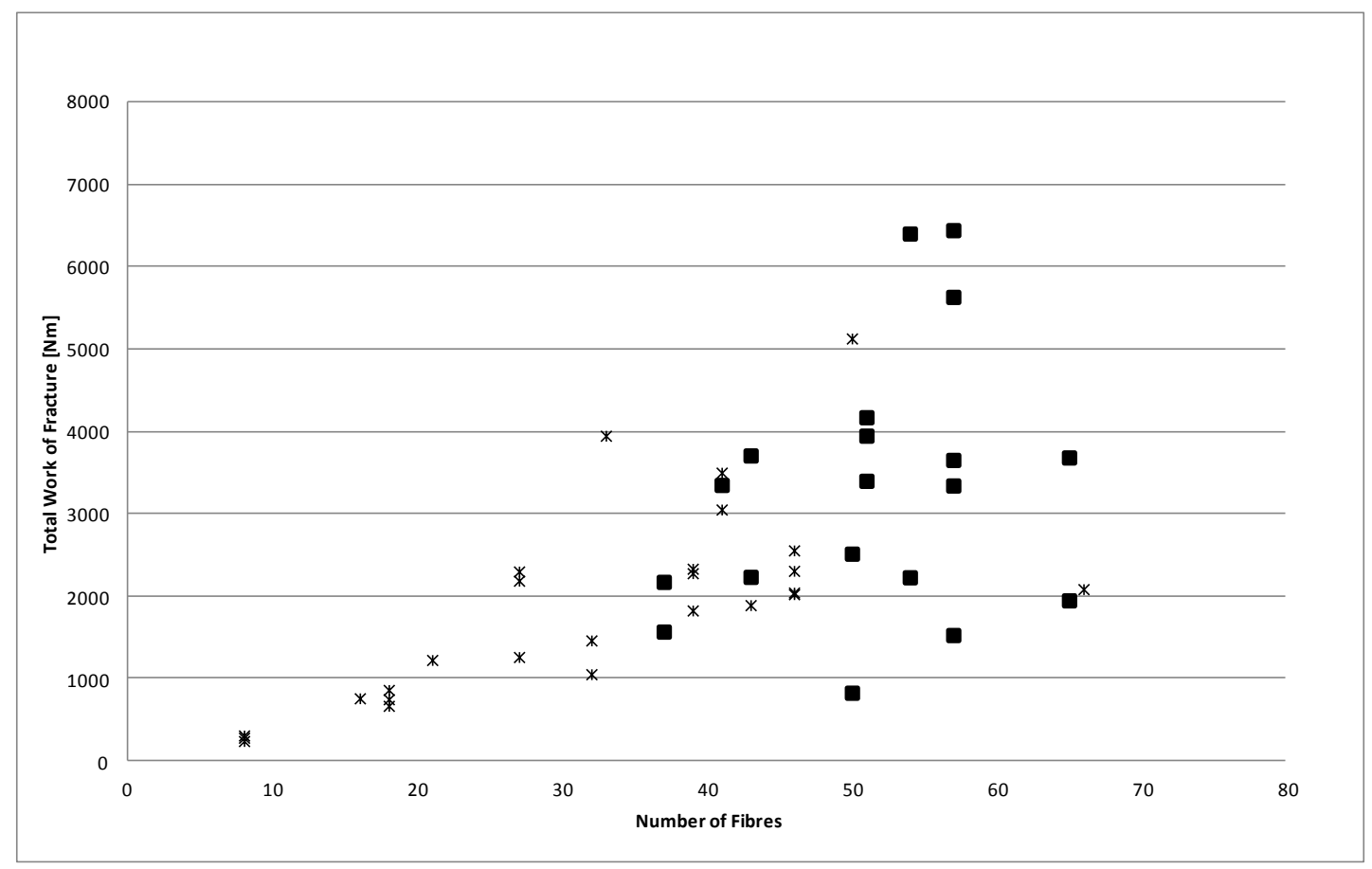

Figure 18. Micro tensile tests on Rayon Fibre bundles- Work of Fracture vs Number of fibres/bundle. ( $*=$ Fractured fibre samples, $\mathbf{\square}=$ Matrix Failure Samples). 


\section{References}

1) J. Meredith. , S.R. Coles., R. Powe., E. Collings., S. Cozien-Cazuc., B.Weager., J. Müssig., K. Kirwan. "On the static and dynamic properties of flax and Cordenka epoxy composites" Composites Science and Technology, May 2013, Volume 80, 17, Pages 31-38.

2) Carbon Fibers \& Carbon Fiber Reinforced Plastics (CFRP) - A Global Market Overview. Pub: PR Newswire: Jan. 16, 2013.

3) Omar Faruka, Andrzej K. Bledzkia, c, Hans-Peter Finkb, Mohini Saind "Biocomposites reinforced with natural fibers: 2000-2010" Progress in Polymer Science, November 2012. Volume 37, Issue 11, , Pages 1552-1596.

4) Bos. H.L.,. van den Oever M.J.A, Peters O.C.J.J., "Tensile and compressive properties of flax fibres for natural fibre reinforced composites" Journal of materials science 200237 pp1683-1692.

5) T. Nilsson and P. J. Gustafsson, "Influence of dislocations and plasticity on the tensile behaviour of flax and hemp fibres", Composites Part A: Applied Science and Manufacturing . (2007) Vol. 38, No. 7, pp. 1722-1728 .

6) M. Müller, C. Riekel, R. Vuong, H. Chanzy. "Skin/core micro-structure in viscose rayon fibres analysed by X-ray microbeam and electron diffraction mapping” Polymer, March 2000. Volume 41, Issue 7,, Pages 2627-2632.

7) A.K. Bledzki, J. Gassan, W. Zhang Impact properties of natural fibre reinforced epoxy foams J Cell Plast, 35 (1999), pp. 550-562.

8) A. K. Mohanty, M. Misra, G. Hinrichsen "Biofibres, biodegradable polymers and biocomposites: An overview". Macromolecular Materials and Engineering March 2000. Volume 276-277, Issue 1, pages 124.

9) B. Bax, J. Müssig: Impact and tensile properties of PLA/Cordenka and PLA/flax composites. In: Composites Science and Technology, (2008), 68 S. 1601-1607.

10) J. Ganster, H.-P. Fink, M. Pinnow, "High-tenacity man-made cellulose fibre reinforced thermoplastics - Injection moulding compounds with polypropylene and alternative matrices" Composites Part A: Applied Science and Manufacturing, October 2006. Volume 37, Issue 10, , Pages 1796-1804.

11) Newman R. "Development of non-wood natural-fibre composites" Chapter 5 pages 193-208 Properties and performance of Natural Fibre Composites Woodhead Publishing Ltd 2008.

12) Huber, T., Müssig, J., Bickerton, S. and Staiger, M.P. "Impact and flexural strength of rayon based all-cellulose composite laminates manufactured via solvent infusion processing". Jeju, Korea: 18th International Conference on Composite Materials (ICCM18), 21-26 Aug 2011.

13) K. Satyanarayana, A. Kulkarni, K. Sukumaran, S. Pillai, K. Cherian, P. Rohatgi "Performance of banana fabric-polyester resin composites" I.H. Marshall (Ed.), Composite structures. Proceedings of the international conference Applied Science, London (1983), pp. 535-548.

14) P. Roe, M. Ansell “Jute reinforced polyester composites. J Mater Sci, 20 (1985), pp. 4015-4020

15) O. Owolabi, T. Czvikovszky, I. Kovacs “ Coconut fibre reinforced thermosetting plastics" J Appl Polym Sci, 30 (1985), pp. 1827-1836 
16)S. Pal, D. Mukhopadhayay, S. Sanyal, R. Mukherjea "Studies on process variables for natural fibre composites - effect of PEAP as interfacial agent” J Appl Polym Sci, 35 (1988), pp. 973-985

17) L. Devi, S. Bhagawan, S. Thomas "Mechanical properties of pineapple leaf fibre-reinforced polyester composites” J Appl Polym Sci, 64 (1997), pp. 1739-1748.

18) A. De Alburquerque, K. Joseph, L. Hecker de Carvalho, J. Morais d'Almeida "Effect of wettability and ageing conditions on the physical and mechanical properties of uniaxially oriented jute-rovingreinforced polyester composites" Compos Sci Technol, 60 (6) (1999), pp. 833-844

19) L. Mwaikambo, E. Bisanda "The performance of cotton/kapok fabric-polyester composites" Polym Testing, 18 (3) (1999), pp. 181-198.

20) C. Santulli "Post-impact damage characterisation on natural fibre reinforced composites using acoustic emission” NDT\&E Int, 34 (8) (2001), pp. 531-536.

21) Tong Yuanjian, D.H. Isaac "Impact and fatigue behaviour of hemp fibre composites" Composites Science and Technology, Volume 67, Issues 15-16, December 2007, Pages 3300-3307.

22) G. Sèbes, N.S. Cetin, C.A.S. Hill, M. Hugues RTM hemp fibre-reinforced polyester composites Appl Compos Mater, 7 (2000), pp. 341-349.

23) D. Rouison, M. Sain, M. Couturier Resin transfer molding of hemp fiber composites: optimization of the process and mechanical properties of the materials Composites Science and Technology, (2006). 66 pp. 895-906.

24) C. Pavithran, P.S. Mukherjee, M. Brahmakumar, A.D. Damodaran "Impact properties of natural fibre composites Composites", 19 (1) (1988), p. 79.

25) Rodriguez E, Petrucci R, Puglia D, Kenny JM, Vazquez (2005) A Characterization of composites based on natural and glass fibers obtained by vacuum infusion Journal Of Composite Materials 39 (3): $265-282$.

26) A K Bledzki, A Jaszkiewicz, M Murr and V E Sperber, T Reußmann, "Processing techniques for natural and wood-fibre composites" Chapter 4 pages 161-192 Properties and Performance of Natural Fibre Composites Woodhead Publishing Ltd 2008.

27) B van Voorn, H.H.G Smit, R.J Sinke, B de Klerk. "Natural fibre reinforced sheet moulding compound "

Composites Part A: Applied Science and Manufacturing, Volume 32, Issue 9, September 2001, Pages 1271-1279.

28) M Huda. L T Drzal, D Ray, A K Mohanty and M Misra, "Natural-fibre composites in the automotive sector" Chapter 7 pages 221-268 Properties and Performance of Natural Fibre Composites Woodhead Publishing Ltd 2008.

29) W. D. (Rik) Brouwer "Natural Fibre Composites Saving Wight and Cost of Renewable Materials" Delft University, Buizerdlaan 39, Nootdorp 2633BH, The Netherlands. Phone: ++31 152782 463; Email: R.Brouwer@lr.tudelft.nl (2008).

30) T. Mei, MR. Piggott. "Mesostructure development during moulding of sheet moulding compounds". Polymer Composites 1996;17:548-55.

31) Dennemann, E., et al. 2009. Fracture Mechanisms in Pavement Design. Pretoria : s.n., 2009

32) JK Kim, YW Mai. "Fracture of CFRP containing impregnated fibre bundles". Composites Science and Technology 1993;49:51-60. 
33) F Meraghni, ML Benzeggagh. "Micromechanical modelling of matrix degradation in randomly oriented discontinuous fibre composites”. Composites Science and Technology 1995;55:171-86.

34) CM Worrall, GM Wells. "Fibre distribution in discontinuous fibre reinforced plastics: characterisation and effect on material performance". In: Proceedings of the Seventh European Conference on Composite Materials, vol. 1, London, 14-16 May. p. 247-52.1996.

35) D. Hull. “An introduction to composite materials”. Cambridge:Cambridge University Press; 1981.

36) R. Burns. "Polyester moulding compounds". New York: Marcel Dekker; 1982.

37) DR Mulligan, SL. Ogin, PA Smith GM Wells, CM, Worrall "Fibre-bundling in a short-fibre composite: 1 Review of literature and development of a method for controlling the degree of bundling" Composites Science and Technology 63 715-725. 